\title{
Hybrid Mathieu Urethroplasty: A Simple Modification Outcomes
}

\section{Mohammad Khirallah Nagi El-dossuky}

Department of Pediatric Surgery, Tanta University, Faculty of Medicine Tanta, Tanta, Egypt
Correspondence: Mohammad Khirallah Department of Pediatric Surgery, Faculty of medicine, Tanta University, El- Geish Street, Tanta, 31527, Egypt

Tel +201003546853

Email Mohamed.khirallah@med.tanta.edu. eg
Background: Distal hypospadias repair is one of the most frequent surgical interventions in the pediatric age group. Successful hypospadias repair should provide a functional penis and good cosmetic results. Mathieu urethroplasty is one of the most popular techniques used. The authors aimed at performing a modification that expanded the scope of indications and improved the final cosmetic results of classic Mathieu urethroplasty.

Methods: Forty-three patients with distal hypospadias were operated by hybrid Mathieu urethroplasty (HMU) during the period from March 2012 to December 2020. All cases had small size glans. Creation of the perimeatal-based flap was performed as Mathieu disrobed. This was followed by the development of glanular wings. The additional step was deep incision of the urethral plate. Then, urethroplasty was performed. The catheter was left in place for 1-3 days.

Results: The mean age was 1.5 years, and the mean operative time was 67 minutes $(60-75$ minutes). The mean size of glans was $12 \mathrm{~mm}(10-15 \mathrm{~mm})$. Fistula developed in three cases. No stricture or meatal regression developed. Infection with disruption of repair occurred in one case. Conclusion: Hybrid Mathieu urethroplasty represents a reliable and successful solution for the cases of distal penile hypospadias with small glans and shallow urethral plate. It increases the scope of candidates of the Mathieu procedure, improves the final cosmetic results and has a reasonable rate of complications.

Keywords: distal hypospadias, Mathieu urethroplasty, modified Mathieu, urethral plate

\section{Background}

Anterior hypospadias represents $65-75 \%$ of all hypospadias cases. There is incomplete development of the anterior part of urethra and it is associated with a less complicated degree of chordee than more proximal types. ${ }^{1}$

The principles of urethroplasty consist of correction of position of meatus, excision of chordee if present, and attainment of satisfactory voiding and sexual activities. $^{2}$ To achieve these goals, several surgical techniques have been described. The most popular procedures of the repair of anterior hypospadias are tubularized incised urethral plate (TIP) and Mathieu procedures. Other choices include transverse island on lay flap (TVIF) and meatal or urethral advancement. $^{3}$

Since Mathieu described his technique during the twentieth century, it became popular worldwide. The glans should be of reasonable size to house the neourethra and the urethral plate should be well developed and deep enough. The disadvantage of Mathieu urethroplasty is the creation of a round or transverse meatus that is not cosmetically accepted. ${ }^{4}$ 
The size of the glans and the urethral plate properties deeply affect the urethroplasty outcome when Mathieu is the preferred choice of surgeons for repair of distal penile hypospadias. So, Mathieu urethroplasty is not indicated when the patient has a small glans and shallow urethral plate. ${ }^{5}$

We aimed at a modification that presented a reliable and effective solution for cases of distal penile hypospadias with small size of the glans and shallow urethral plate. Hence, increasing the overall candidates of Mathieu procedure.

\section{Patients and Methods}

This study was a prospective study in two tertiary level hospitals. It was carried out during the period from March 2012 to December 2020. The study had approval code $(34403 / / 1 / 21)$ of the research ethics committee. The study was conducted in accordance with the Declaration of Helsinki. The parents or legal guardians of the patients provided informed consent.

The study included 43 patients with distal penile hypospadias (coronal, subcoronal and distal penile). All these cases were not suitable candidates for classic Mathieu procedure due to either shallow urethral plate or small glans size (less than $15 \mathrm{~mm}$ in maximum width). Cases that had failed previous surgery for distal penile hypospadias were excluded. No local or systemic testosterone was used.

\section{Operative Details}

We measured the glans size by measuring the distance between the widest two points of glanular knuckles without stretching the glans with stay suture (Figure 1).

Operative steps were the same as described for Mathieu. Authors added a deep incision of urethral plate to the procedure. This incision deeply extended along the whole length of the plate. This incision together with good

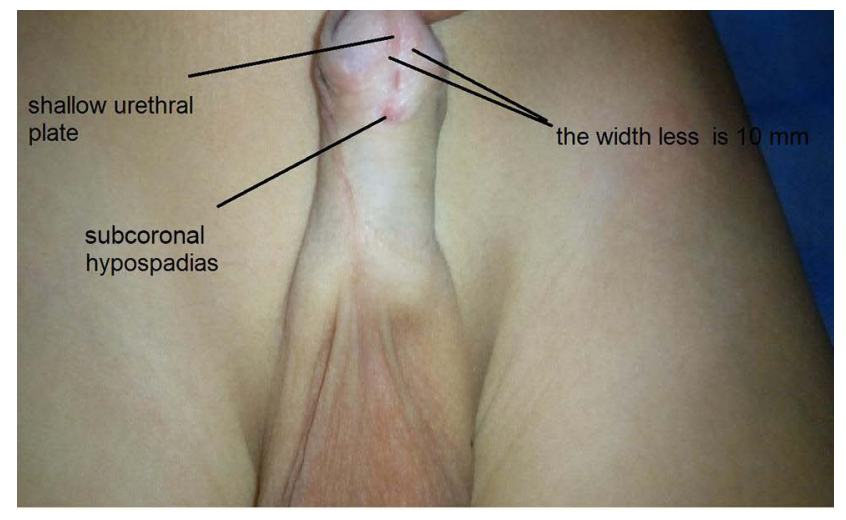

Figure I Subcoronal hypospadias with glanular wings less than $10 \mathrm{~mm}$ and shallow urethral plate. mobilization of glanular wings allowed glans to negotiate the neourethra and be closed without tension. Urethroplasty was performed using either polyglactin suture size $6 / 0$ or PDS sutures size 6/0. Sutures were taken in subcuticular manner. No additional investing layer was needed. Non selfretaining catheter size ( 6 or 8 ) was used for 3-5 days postoperatively. Skin over the shaft of penis was closed on the ventral aspect. Circumcision was postponed in uncircumcised children. Local antibiotic cream (aminoglycosides) was applied with the dressing for 5 days (Figure 2).

All children had postoperative follow up at one week, one month, three months and six months (Figure 3).

Children that were scheduled to have circumcision, were operated six months after the first operation (Figure 4).

The parameters of follow up were the character of the stream of urine (single, strong, forward, spray or dripping), site and shape of meatus, and development of complications (fistula, stenosis, failed repair). Hypospadias

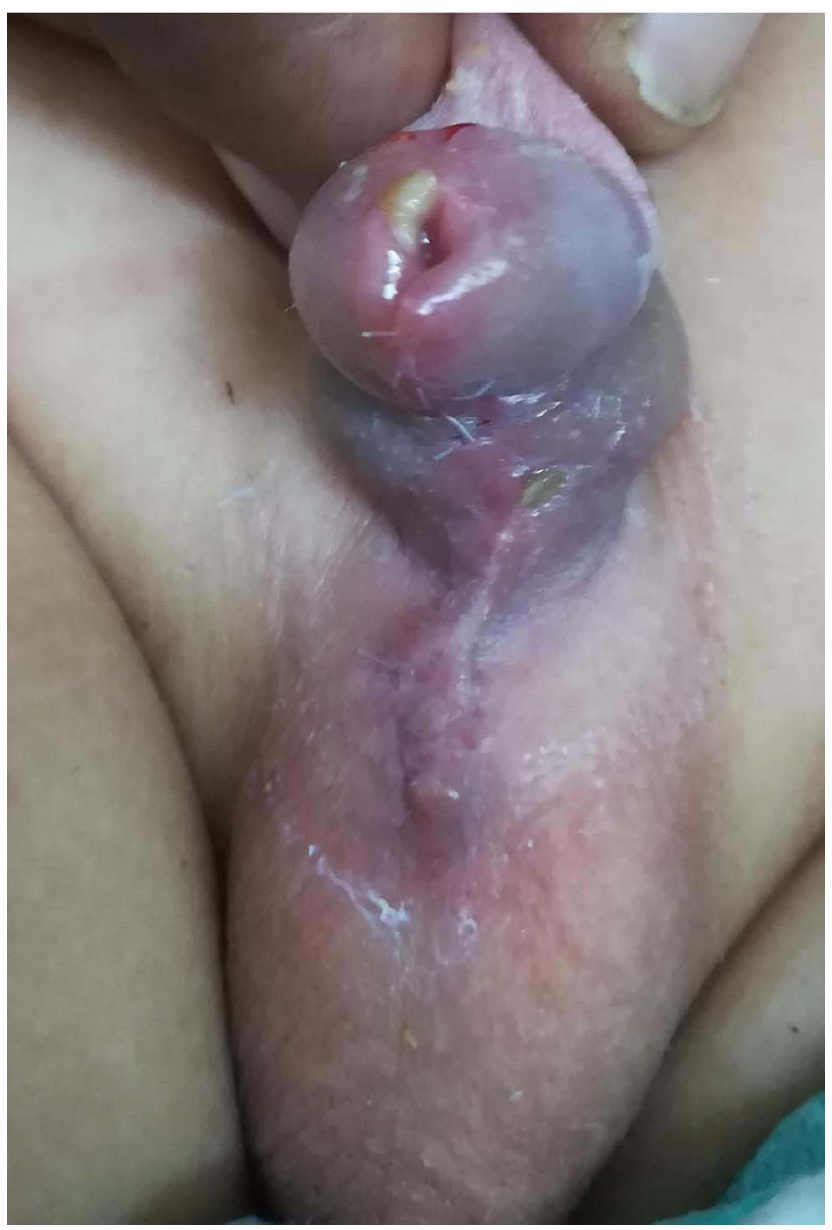

Figure 2 Early postoperative photo on day 5 postoperative. 


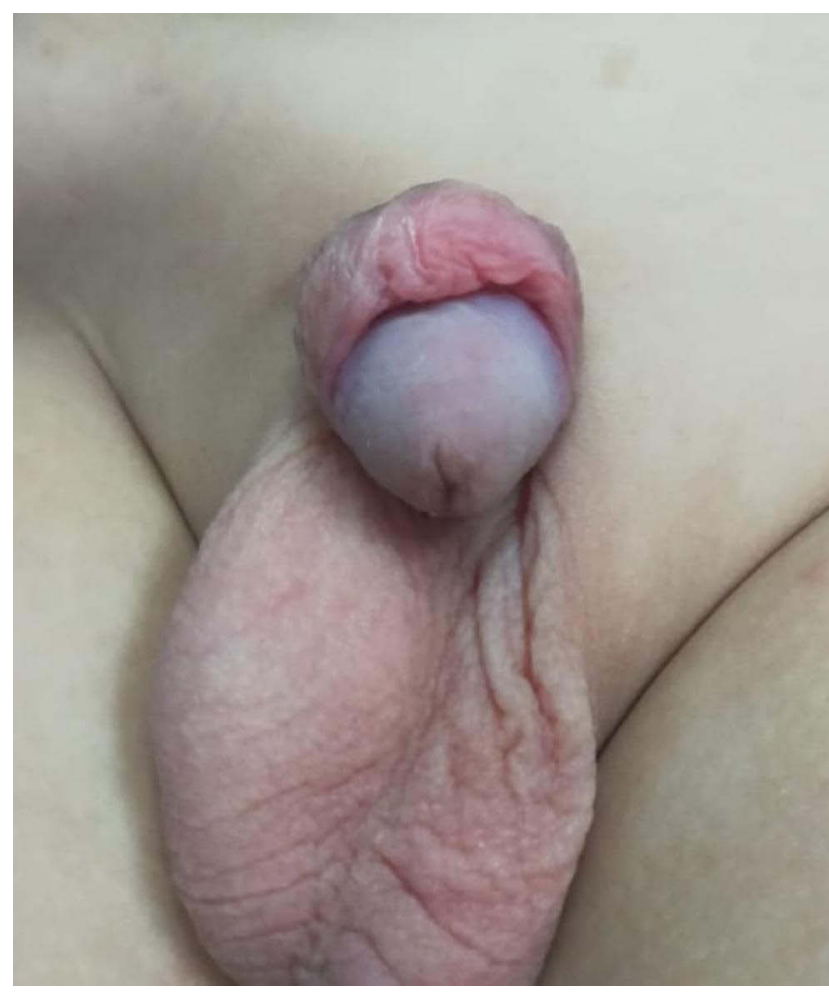

Figure 3 Six months postoperative with the meatus in slit-like shape and vertical orientation.

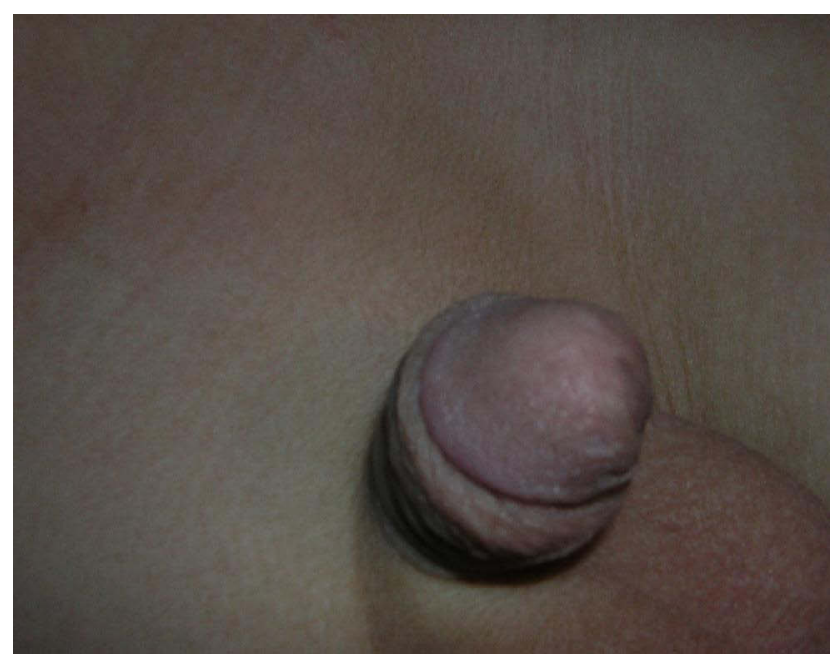

Figure 4 Final appearance post circumcision.

Objective Scoring Evaluation (HOSE) was used to evaluate the final outcomes after repair. ${ }^{6}$

\section{Results}

Forty-three patients with distal hypospadias (coronal, subcoronal and distal penile) were operated using HMU. The mean age at operation was 1.5 years ( 6 months -3 years)
The mean width of glans was $12 \mathrm{~mm}(8-15 \mathrm{~mm})$. Thirteen patients (30.23\%) were circumcised. All cases had shallow urethral plate. Ten cases $(23.25 \%)$ were coronal, 28 cases (65.11\%) were subcoronal and 5 cases $(11.6 \%)$ were distal penile. The mean operative time was 67 minutes (60-75 minutes). The mean length of the perimeatal-based flap was $1.5 \mathrm{~cm}(1.2-1.8 \mathrm{~cm})$ (Table 1).

The mean duration of urinary catheter was 2 days (1-4 days). The stream of urine was single, strong and forward in $35(81.3 \%)$ of cases. Dripping found in four $(9.3 \%)$ cases and four (9.3\%) cases had spray stream. Fistula had developed in three $(6.9 \%)$ cases. Complete disruption and failed repair occurred in one (2.3\%) case. No cases developed either meatal stenosis or meatal regression (Table 2).

By application of HOSE we found 31 cases that achieved 16, 8 cases achieved 15, 3 cases achieved 14 and one case achieved 9 (Table 3 ).

\section{Discussion}

Although distal penile hypospadias represents a simple and a common form of hypospadias, there are hundreds of operations that were designed to manage it. None of them can be described as the standard or the golden choice for urethroplasty. Each center has its own experience and preference that constitute its management policy of cases of distal penile hypospadias. As a rule, every surgeon practices what he/she masters. $^{7}$

During the 1930s, Mathieu described his procedure to achieve the main objectives of successful hypospadias repair using pre-meatal based flap. Its philosophy depends on the good blood supply of the flap through the premeatal vascular supply. ${ }^{8}$

Table I Preoperative and Operative Data

\begin{tabular}{|l|l|}
\hline Variable & Values \\
\hline Age & 1.5 years (6 months-3 years) \\
\hline Size of glans & $12 \mathrm{~mm}(8-15 \mathrm{~mm})$ \\
\hline $\begin{array}{l}\text { Prepuce } \\
\text { Circumcised } \\
\text { Uncircumcised }\end{array}$ & $13(30.23 \%)$ \\
\hline $\begin{array}{l}\text { Meatal position (No. of cases and \%) } \\
\text { Coronal } \\
\text { Subcoronal } \\
\text { Distal penile }\end{array}$ & $\begin{array}{l}10(23.25 \%) \\
28(65.11 \%) \\
5(11.6 \%)\end{array}$ \\
\hline Operative time (minutes) & 67 minutes $(60-75$ minutes) \\
\hline Length of the perimeatal-based flap (cm) & $1.5 \mathrm{~cm}(1.2-1.8 \mathrm{~cm})$ \\
\hline
\end{tabular}


Table 2 Postoperative Data

\begin{tabular}{|l|l|}
\hline Variable & Values \\
\hline Duration of urethral stent (days) & 2 days (I-4 days) \\
\hline $\begin{array}{l}\text { Steam of urine (No. of cases and \%) } \\
\text { Single, strong and forward }\end{array}$ & $35(81.3 \%)$ \\
Dripping & $4(9.3 \%)$ \\
Spray stream & $4(9.3 \%)$ \\
\hline Fistula (No. of cases and \%) & $3(6.9 \%)$ \\
\hline Failed repair (No. of cases and \%) & One (2.3\%) \\
\hline Meatal stenosis (No. of cases and \%) & No cases \\
\hline Meatal regression (No. of cases and \%) & No cases \\
\hline
\end{tabular}

Table 3 HOSE Score of HMU Cases

\begin{tabular}{|l|l|}
\hline HOSE Score & No. of Cases and \% \\
\hline 16 & 31 cases $(72 \%)$ \\
15 & 8 cases $(18.6 \%)$ \\
14 & 3 cases $(6.9 \%)$ \\
9 & One case $(2.3 \%)$ \\
\hline
\end{tabular}

Abbreviations: HOSE, hypospadias Objective Score Evaluation; HMU, hybrid Mathieu urethroplasty.

Despite gaining popularity over many years, there were some conditions that may contraindicate its practice. Apart from the proximal location of meatus, the presence of shallow urethral plate and small size of glans represented the main contraindication of Mathieu urethroplasty. The presence of small glans during classic Mathieu urethroplasty leads to exertion of more tension on the glanular wings over the created tube. This tension will lead to edema, impaired healing, dehiscence of the glans and failure of procedure. ${ }^{5}$

In the same context Salem and Nilamani excluded cases of distal hypospadias with narrow glanular groove or shallow urethral plate from cases with classic Mathieu urethroplasty. They reported increased incidence of both fistula and meatal stenosis when these cases were operated with the classic Mathieu urethroplasty. ${ }^{9,10}$

To deal with these contraindications we freely mobilized the glanular wings and deeply incised the shallow urethral plate. This helped us in two ways. The first was the repair of the glans over the created tube without tension. The second was the suturing of the flap to the edges of incised urethral plate which helped us to overcome the problems of the meatal stenosis or disruption of the repair. This was due to the extra width which had been added by our technique to the developing tube. When we applied these principles, the incidence of fistula or disruption was recorded to develop in cases of glanular width less than $10 \mathrm{~mm}$.

This is in contrast to what happens during TIP procedure in cases with small size of the glans and shallow urethral plate, where the anastomosis is performed between the edges of incised plate only without any additional width, so the repair is more liable to stenosis and increased incidence of disruption.

Holland documented a high rate of post TIP complications if the procedure was performed in children with small glans or shallow urethral plate. The most common complication was the development of meatal stenosis. ${ }^{4}$

The relation of the size of the glans and the outcome of hypospadias surgery is considered a matter of debate among hypospadias surgeons worldwide. Bush et al. reported that the size of the glans was an independent factor of developing complications following urethroplasty. Although they reached that conclusion when comparing the results of urethroplasty using TIP procedure in both distal and proximal, it was clear that small size of the glans in distal penile hypospadias showed higher rate of urethra-cutaneous fistula. Bush et al. showed that the incidence of the complications increased when the width of the glans was less than $12 \mathrm{~mm}^{11}$

The study of the glans size and urethral plate attracted the attention of Merriman et al. to reach a conclusion about the effect of this glans size and urethral plate complex on the results and complications of hypospadias repair. They concluded that small size of the glans is associated with increased incidence of fistula. They assumed an observational score to predict cases that may develop complications on the basis of glans size, meatal position and the shaft of the penis. ${ }^{12}$

On the other hand, Faasse reported his experience with 159 cases of hypospadias. The width of the glans ranged from 10-22 $\mathrm{mm}$. He documented that the size of glans was not associated with increased incidence of complications. He claimed that there are other factors that may be associated with the development of complications. He concluded that further evaluation and study of these factors may help prediction of cases that may develop post repair complications. $^{13}$

The incision of urethral plate during HMU helped the meatus to be oriented in vertical slit-like shape at the tip of the glans. As a result, the final cosmetic appearance was improved when evaluated using HOSE score. Although the appearance of the meatus is greatly improved, we do 
not recommend the application of HMU in classic cases of Mathieu urethroplasty. There will be more disfigurement of the meatus which will be very wide and looks like a mega meatus anomaly.

According to the available data there are few reports discussing the combination of the principles of both TIP and Mathieu urethroplasties. One of them was that of Khalil et al. They compared the results of both TIP and Mathieu technique with incision of urethral plate. They excluded cases with shallow urethral plate as these cases were not suitable candidates for classic Mathieu procedure. $^{14,15}$

Although these previous studies reported the experience with modified Mathieu procedure by incising the urethral plate, their concept was improving the outcomes of TIP urethroplasty, that became more popular, by combining its principles with those of Mathieu procedure. They succeeded to document the reduction of rate of fistula and meatal stenosis that were considered the most common complications of TIP urethroplasty.

The limitations of the current study were the small size of the sample and being a prospective not randomized control study with the most popular TIP technique.

\section{Conclusion}

Hybrid Mathieu urethroplasty is a reliable and successful modification. It increased the scope of selection of cases of Mathieu procedure and improved the final cosmetic results. Also, this modification had a reasonable rate of complications.

\section{Data Sharing Statement}

The datasets used and/or analyzed during the current study are available from the corresponding author on reasonable request.

\section{Ethical Approval and Consent to Participate}

Approval was obtained from the Research Ethics committee of Tanta University Faculty of Medicine with approval code $(34403 / / 1 / 21)$. The parents or legal guardians of the patients provided informed consent. The study was conducted in accordance with the Declaration of Helsinki. A written consent was obtained from study participants.

\section{Consent for Publication}

Agree to consent for publication.

\section{Author Contributions}

Both authors made a significant contribution to the work reported, whether that is in the conception, study design, execution, acquisition of data, analysis and interpretation, or in all these areas; took part in drafting, revising or critically reviewing the article; gave final approval of the version to be published; have agreed on the journal to which the article has been submitted; and agree to be accountable for all aspects of the work.

\section{Funding}

There is no funding to report.

\section{Disclosure}

The authors report no conflicts of interest in this work.

\section{References}

1. Winslow BH, Devine CJ. Principles in repair of hypospadias. Semin Paediatr Surg. 1996;5:41.

2. Vallasciani S, Spangnoli A, Borsellino A, Martini L, Ferro F. Simplifying in surgical approach to glanular and coronal hypospadias: longitudinal urethral incision and glansoplasty. J Pediatr Urolo. 2007;3:453-456. doi:10.1016/j.jpurol.2007.06.004

3. Elbakry A. Tubularized-incised urethral plate urethroplasty: is regular dilatation necessary for success. BJU Int. 1999;84:683-688. doi:10.1046/j.1464-410x.1999.00207.x

4. Holland A, Smith G. Effect of the depth and width of the urethral plate on tubularized incised plate urethroplasty. $J$ Urol. 2000;164:489-491. doi:10.1016/S0022-5347(05)67408-3

5. Wilkinson DJ, Farrelly P, Kenny SE. Outcomes in distal hypospadias: a systemic review of the Mathieu and tubularized incised plate repairs. $J$ Pediatr Urol. 2012;8:307-312. doi:10.1016/j. jpurol.2010.11.008

6. Holland AJA, Smith GH, Ross FI, Cass DT. HOSE: an objective scoring system for evaluating the results of hypospadias surgery. $B J U$ Int. 2000;88:255-258. doi:10.1046/j.1464-410x.2001.02280.x

7. Yesildag E, Tekant G, Sarimurat N, Buyukunal SN. Do patch procedures prevent complications of the Mathieu technique? J Urol. 2004;171:2623-2625. doi:10.1097/01.ju.0000112781.93314.f3

8. Mathieu P. Traitement en un temps de I 'hypospadias balanique on juxtabalanique. $J$ Chir. 1932;39:481-486.

9. Salem HK, Shelbaia A, Elnashar A. Combined use of Mathieu and incised plate technique (Snodgrass technique) for repair of distal hypospadias in older children. Afr $J$ Urol. 2013;19:74-77. doi:10.1016/j.afju.2013.02.006

10. Nilamani M, Bhusan NB, Annadaprasad P. Combined use of the Mathieu and incised urethral plate techniques for repair of distal penile hypospadias. Ind J Surg. 2015;77:694-697. doi:10.1007/ s12262-013-0988-z

11. Bush N, Villanueva C, Snodgrass W. Glans size is an independent risk factor for urethroplasty complications after hypospadias repair. J Ped Urol. 2015;11:355e1-355e5. doi:10.1016/j.jpurol.2015.05.029

12. Merriman LS, Angela M, Arlen AM, et al. The GMS hypospadias score: assessment of inter-observer reliability and correlation with post-operative complications. J Pediatr Urol. 2013;9:707-712. doi:10.1016/j.jpurol.2013.04.006 
13. Faasse MA, Johnson EK, Bowen DK, et al. Is glans penis width a risk factor for complications after hypospadias repair? $J$ Pediatr Urol. 2016;12:202e1-202e5. doi:10.1016/j.jpurol.2016.04.017

14. Khalil M, Gharib T, El-shaer W, Sebaey A, Elmohamdy B, Elgamal K. Mathieu technique with incision of the urethral plate versus standard tubularized incised plate urethroplasty in primary repair of distal hypospadias: a prospective randomized study. African J Urol. 2017;15:242-247. doi:10.1016/j.aju.2017.03.007
15. Cook A, Khoury A, Neville C, Bagli DJ, Farhat WA, Pippi Salle JL. A multicenter evaluation of technical preferences for primary hypospadias repair. $J$ Urol. 2005;174:2354-2357. doi:10.1097/01. ju.0000180643.01803.43

\section{Publish your work in this journal}

Research and Reports in Urology is an international, peer-reviewed, open access journal publishing original research, reports, editorials, reviews and commentaries on all aspects of adult and pediatric urology in the clinic and laboratory including the following topics: Pathology, pathophysiology of urological disease; Investigation and

Submit your manuscript here: https://www.dovepress.com/research-and-reports-in-urology-journal treatment of urological disease; Pharmacology of drugs used for the treatment of urological disease. The manuscript management system is completely online and includes a very quick and fair peer-review system, which is all easy to use. Visit http://www.dovepress.com/ testimonials.php to read real quotes from published authors. 